\title{
Development Work on a New Package Design for the Next Generation Microelectronics
}

* Federal Manufacturing \& Technologies

B. E. Adams, FM\&T, and

V. DeMarco, Micro-Mode Products

KCP-613-5853

Published November 1996

Final Report

Approved for public release; distribution is unlimited.

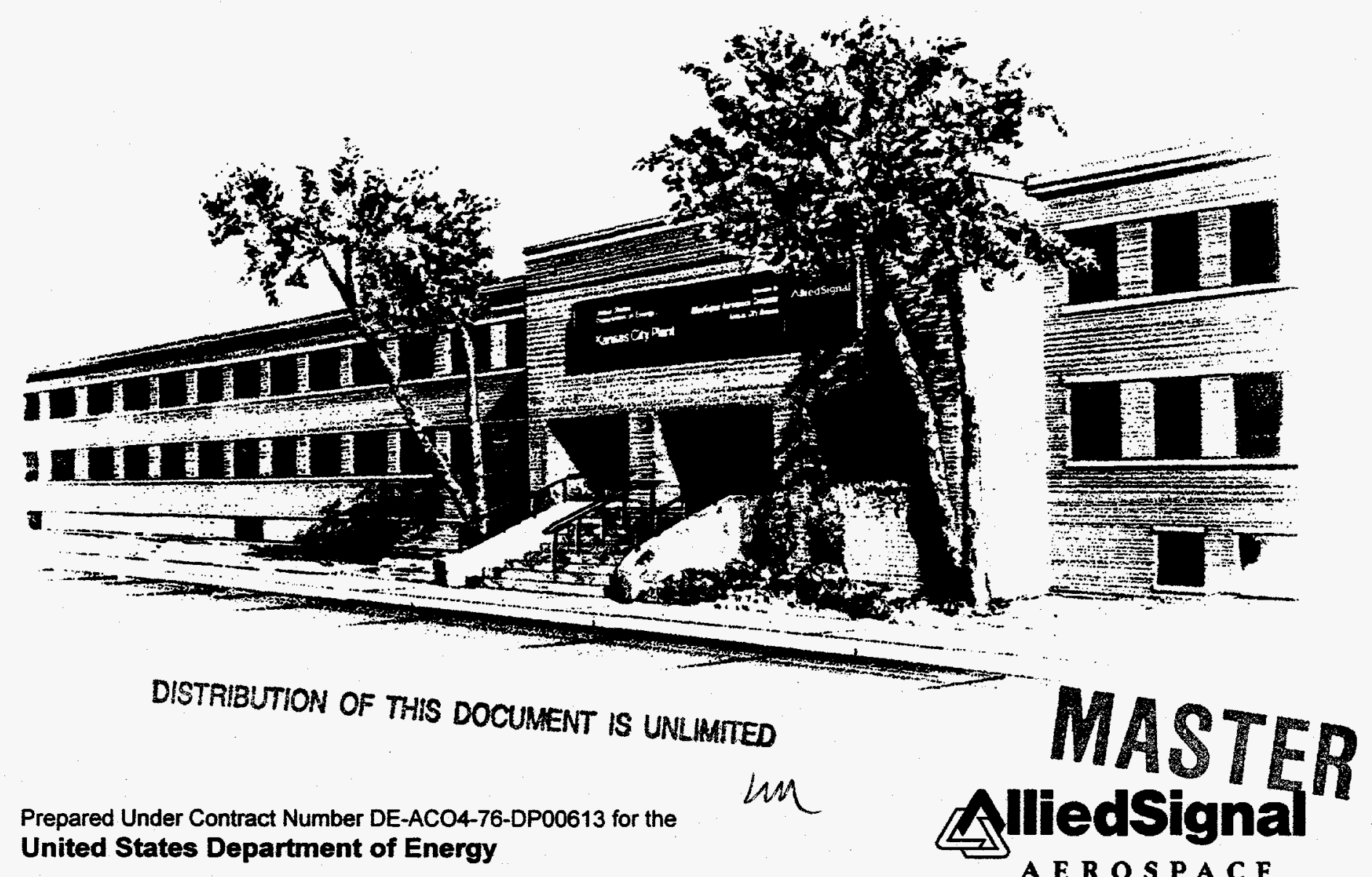




\section{DISCLAIMER}

This report was prepared as an account of work sponsored by an agency of the United States Government. Neither the United States Government nor any agency thereof, nor any of their employees, makes any warranty, express or implied, or assumes any legal liability or responsibility for the accuracy, completeness, or usefulness of any information, apparatus, product, or process disclosed, or represents that its use would not infringe privately owned rights. Reference herein to any specific commercial product, process, or service by trade names, trademark, manufacturer, or otherwise, does not necessarily constitute or imply its endorsement, recommendation, or favoring by the United States Government or any agency thereof. The views and opinions of authors expressed herein do not necessarily state or reflect those of the United States Government or any agency thereof.

Printed in the United States of America.

This report has been reproduced from the best available copy.

Available to DOE and DOE contractors from the Office of Scientific and Technical Information, P. O. Box 62, Oak Ridge, Tennessee 37831; prices available from (615) 576-8401, FTS 626-8401.

Available to the public from the National Technical Information Service, U.S. Department of Commerce, 5285 Port Royal Rd., Springfield, Virginia 22161. 


\section{DISCLAMMER}

Portions of this document may be illegible in electronic image products. Images are produced from the best available original document. 
KCP-613-5853

Distribution Category UC-706

Approved for public release; distribution is unlimited.

\section{DEVELOPMENT WORK ON A NEW PACKAGE DESIGN FOR THE NEXT GENERATION MICROELECTRONICS}

B. E. Adams, FM\&T, and

V. DeMarco, Micro-Mode Products

Published November 1996

Final Report

Small Business Initiative

Cooperative Research and Development Agreement with Micro-Mode Products 


\section{Contents}

Section

Page

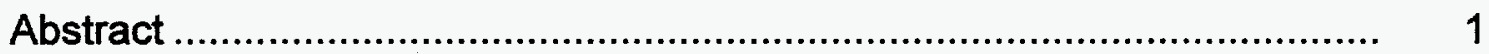

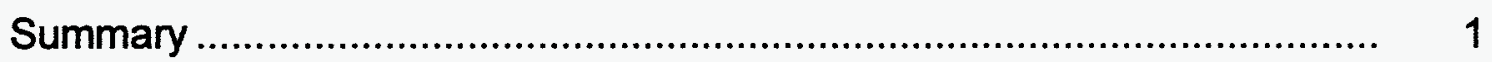

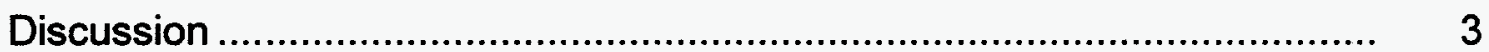

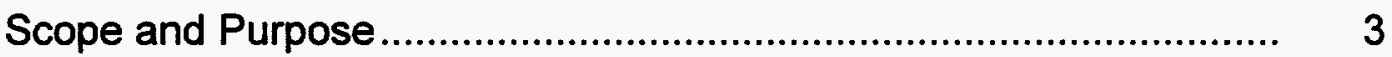

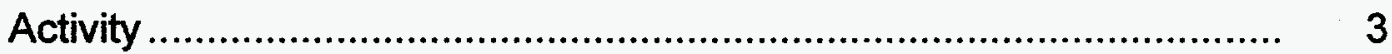

Introduction ....................................................................... 3

Micro-Mode Product's Results.................................................. $\quad 4$

AlliedSignal's Results ......................................................... 4

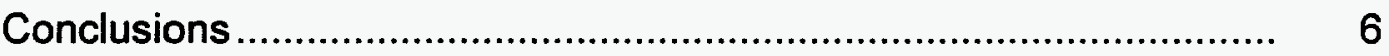

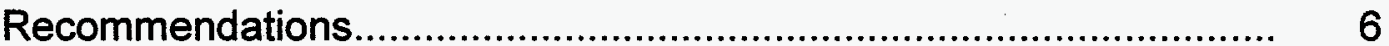

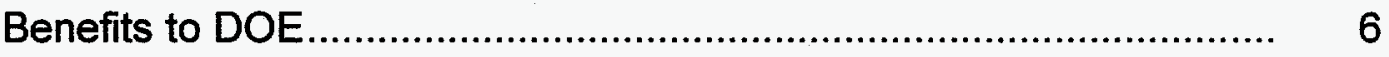




\section{Abstract}

AlliedSignal Federal Manufacturing \& Technologies and Micro-Mode Products joined under a Department of Energy Cooperative Research and Development Agreement (CRADA) to develop a new package for next generation electronics devices. Requirements included low cost of manufacture, ability to satisfy thermal expansion requirements, ability to satisfy thermal dissipation requirements, acceptable digital and microwave performance, and hermeticity. Within the time limitation of the CRADA, four processes were tested: vacuum deposition of paralene, epoxy powder coating, transfer molding, and manual encapsulation. Transfer molding and manual potting showed improvement in hermeticity of the package but demonstrated microcracking and reduced heat transfer ability following encapsulation. Additional studies in manufacturing and encapsulating of the package are recommended.

\section{Summary}

Micro-Mode Products (MMP), a minority corporation employing 65 persons, was interested in developing a new package for the next generation electronic devices. The company's objective was to prove the feasibility of a packaging concept which will satisfy the basic requirements:

1. low cost of manufacture,

2. ability to satisfy thermal expansion requirements,

3. ability to satisfy thermal dissipation requirements,

4. acceptable digital and microwave performance, and

5. hermeticity.

MMP was to select the package materials, fabricate the pieces, and manufacture the packages. AlliedSignal was to develop a coating process to ensure the hermeticity of the new package. MMP's first material selection for a package base was AISiC machined to the final dimension of the package design. However, because of poor adhesion of the gold plating to the AISiC, it was replaced with copper. The next technical challenge was attaching the dielectric material to the copper base. During initial helium leak testing, adhesion failure between the metal base plate and the first dielectric gasket was experienced. This problem required either an alteration of the molding equipment or the use of an alternative dielectric material. Although an alternative material was the desirable option, MMP was not in a position to investigate the new material because of time and financial constraints. MMP was unable to deliver packages to AlliedSignal within the time constraint of the Cooperative Research and Development Agreement (CRADA) to meet their portion of the agreement. 
Without the use of the packages from MMP, AlliedSignal substituted kovar packages to develop a coating process. Two processes, transfer molding and manual potting, were developed that initially met the hermeticity requirements of military standard 883D. However, due to the mismatch in thermal coefficient of expansion (TCE), after 40 temperature cycles from $-55^{\circ} \mathrm{C}$ to $150^{\circ} \mathrm{C}$, the packages which were transfer molded with a thermoplastic formed microcracks and the hermetic seal began to degrade. Although the epoxy-potted parts were not temperature cycled, the same concern of microcracking exists. The other concern with both of these coating processes is the reduced heat transfer ability of the package once it is encapsulated. Both processes coat the package with a material thickness between $1 / 8$ and $1 / 4$ inch. The epoxy and the thermoplastic do not transfer heat as well as the AISiC or copper base material of the package. 


\section{Discussion}

\section{Scope and Purpose}

The purpose of the Cooperative Research and Development Agreement (CRADA) between Micro-Mode Products (MMP) and AlliedSignal Federal Manufacturing \& Technologies (FM\&T) was to develop a new package to be used in the microelectronics industry. The package was to be designed to met the enhanced requirements for microwave technology which included

1. low cost of manufacture,

2. ability to satisfy thermal expansion requirements,

3. ability to satisfy thermal dissipation requirements,

4. acceptable digital and microwave performance, and

5. hermeticity.

MMP was to develop and manufacture the basic package, and AlliedSignal was to develop a coating process to ensure hermeticity.

\section{Activity}

\section{Introduction}

Micro-Mode Products (MMP), a minority corporation employing 65 persons, was interested in developing a new package for the next generation electronic devices. The company's objective was to prove the feasibility of a packaging concept leading to the manufacturability of hermetic packages which will satisfy the basic requirements of commercial and military industry.

To meet these requirements, MMP suggested manufacturing a package consisting of four discrete elements: the base, the dielectric frame, the lead frame, and the lid. The base would be made of a material which would meet the thermal expansion and thermal conductivity requirements needed. The initial selection was aluminum silicon carbide. The process to manufacture the base would be stamping. The typical thickness of the plated base would range from $0.015^{\prime \prime}$ to $0.020^{\prime \prime}$. The dielectric frame was to be fabricated from a Rogers Corporation proprietary material which has been formulated to exhibit low permitivity at microwave frequencies. The lead frames would be the standard gold-plated copper currently used in manufacturing. Finally, the lid could be kovar, ceramic, aluminum silicon carbide or other material.

The package would be manufactured by stacking the base, dielectric frame, and lead frames, placed in the appropriate fixture and bonded together using the appropriate heat and pressure. A die could then be soldered to the base and wire bonded to the lead frames. Finally, the lid could be attached by epoxy. 
The package would then require an external encapsulating or coating process that would make it hermetic. The objective would be to meet or exceed a leak rate of $10^{-8} \mathrm{~cm}^{3} / \mathrm{min}$ of helium.

\section{Micro-Mode Product's Results}

MMP was to select the package materials, fabricate the pieces, and manufacture the packages. MMP purchased the AISiC already machined to the final dimension of the package design. However, the desired adhesion of the gold plating could not be achieved, so the AISiC was replaced with copper. The next technical challenge was attaching the dielectric material to the copper base. During initial helium leak testing, adhesion failure between the metal base plate and the first dielectric gasket was occurring. This problem required either an alteration of the molding equipment or the use of an alternative dielectric material. Although an alternative material was the desirable option, MMP was not in a position to investigate the new material because of time and financial constraints. MMP was unable to deliver packages to AlliedSignal for its portion of the CRADA.

\section{AlliedSignal's Results}

AlliedSignal was to develop a coating process and verify the hermeticity of the packages before and after aging. In the absence of the actual packages that were being developed by MMP, AlliedSignal substituted kovar packages to develop a coating process. Four processes were tested: vacuum deposition of paralene, epoxy powder coating, transfer molding, and manual encapsulation.

\section{Vacuum Parylene Coating Process}

Parylene coating was the first process studied for encapsulating the microelectronic packages. The process deposits a very thin layer of parylene over the entire surface. Parylene will also penetrate small openings in the seal ring and coat the interior components. The coating thickness ranges from 10 to 25 microinches. Ten one-inch-square kovar packages with soldered kovar lids were fine and gross leak tested and separated into three groups. The groups were those that passed the $10^{-8} \mathrm{~cm}^{3} / \mathrm{min}$ fine leak rate of helium, those that failed the fine leak rate, and those that failed gross leak testing. The packages were then parylene coated in a vacuum chamber. The packages were leak tested again. No reduction in the leak rate was observed for any package. Therefore, parylene coating was eliminated as a potential coating process.

\section{Epoxy Powder Coating}

Powder coating is a process which is run at elevated temperature and atmospheric pressure. The package is placed in a vented hood, grounded, and then sprayed with an epoxy powder. As the powder is sprayed, it generates an electric charge. The powdered epoxy will stick to the package due to electrostatic attraction. To improve the adhesion of the epoxy to the packages, the packages were plasma cleaned prior to coating. The epoxy was then cured on the 
packages. Ten one-inch-square kovar packages with soldered kovar lids were fine and gross leak tested and separated into three groups. The groups were those that passed the $10^{-8} \mathrm{~cm}^{3} / \mathrm{min}$ fine leak rate of helium, those that failed the fine leak rate, and those that failed gross leak testing. The packages were then epoxy powder coated. The combination of plasma cleaning and powder coating weakened the solder seal between the package and lid. This joint would fail on a small percentage of the packages. The end result is that epoxy powder coating is not a viable process for encapsulating the packages. The packages that did not have solder seal failures were leak tested again. No improvement in leak testing was observed.

\section{Transfer Molding}

Transfer molding is an encapsulation process that uses heat and pressure to mold a thermoplastic material around an object. The object, in this case a kovar package, is placed in a mold which is positioned on a large press. A cylinder of thermoplastic material is then heated and compressed by a piston. The material under the heat and pressure will liquefy and flow through channels in the mold containing the package. The material is then cooled inside the mold and solidifies, encapsulating the package.

Five packages were successfully encapsulated by transfer molding and passed initial leak testing. However, after 40 temperature cycles from $-55^{\circ} \mathrm{C}$ to $150^{\circ} \mathrm{C}$, microcracks began to develop in the thermoplastic and packages began to fail fine leak testing. The microcracks formed because of the difference in thermal expansion coefficients of the kovar and thermoplastic. Another concern when encapsulating by this process is the thermal insulating effect of the plastic which impedes heat transfer.

\section{Potting}

The final process investigated was a potting process using an epoxy resin. A mold was made from Teflon and lined with aluminum foil. Epoxy was injected into the two halves of the mold. The kovar package was placed in the epoxy-filled mold, and the mold was closed and clamped shut. The mold containing the encapsulated part was then placed in an oven and cured at $150^{\circ} \mathrm{C}$ for 24 hours. Five packages were successfully encapsulated by this process; however, visual examination indicated a large quantity of air bubbles trapped in the mold. The trapped air can be eliminated by altering the potting process. The package should first be clamped into the mold. Then by evacuating the mold prior to injecting the epoxy, a minimum of air would be trapped in the mold. The encapsulated packages were leak tested, and all five passed initial fine and gross leak testing. Temperature cycling was not performed on these parts. 


\section{Conclusions}

Of the four processes tested only two, transfer molding and manual potting, showed an improvement in hermeticity of the package. However, due to the mismatch in thermal coefficient of expansion (TCE), after 40 temperature cycles from $-55^{\circ} \mathrm{C}$ to $150^{\circ} \mathrm{C}$, the packages which were transfer molded with a thermoplastic formed microcracks and the hermetic seal began to degrade. Although the epoxy-potted parts were not temperature cycled, the same concern of microcracking exists. The other concern with both of these coating processes is the reduced heat transfer ability of the package once it is encapsulated. Both processes coat the package with a material thickness between $1 / 8$ and $1 / 4$ inch. The epoxy and the thermoplastic do not transfer heat as well as the AISiC or copper base material of the package.

\section{Recommendations}

Further studies need to be made, both in the manufacturing of the package as well as encapsulating the package, before consideration for production. The organic encapsulants tested all have thermal expansion mismatches and thermal conduction concerns to overcome. One potential encapsulant not studied was an inorganic glass. The technical concern with the glass material is the high glass transition temperature which must be exceeded to encapsulate a part. The temperature extreme may be too high for the wire bonded die inside the package.

\section{Benefits to DOE}

Although the project was not successful in developing the desired package, the DOE benefited from the work in two areas. First, several coating processes were tested for electronic packaging. Second, AlliedSignal was able to maintain core competence in the packaging department by building prototype packages for the coating study. 
DOE POINT OF CONTACT FOR PROJECT INFORMATION:

Program Office DOE/KCAO

Name

Kenneth H. Bauer

Title

Telephone

Manufacturing and Operations Branch

Address

(816) $997-3917$

POB 410202-1D49

Kansas City, MO 64141-0202

Facsimile

(816) 997-5059

Internet E-mail Address kbauer@kcp.com

Laboratory AlliedSignal Federal Manufacturing \& Technologies

COMPANY SIZE AND POINT OF CONTACT:

Non-Federal Participant

Organization Name Micro-Mode Products, Inc.

Type

Minority Small Business

Point of Contact Vincent DeMarco

President

Address

1870 John Towers Ave.

Telephone

El Cajon, CA 92020

Facsimile

(619) 449-3844

(619) 258-8701 